\title{
Modelling the learning impacts of educational disruptions in the short and long run. *
}

\author{
Luis Monroy-Gómez-Franco ${ }^{\dagger}$
}

March, 2022

\begin{abstract}
In this paper, I propose a new framework for analysing the short and long-run effects of temporary educational disruptions on the learning progression of children. The framework integrates into a coherent model recent advances in the literature on learning acquisition (Kaffenberger, 2021; Kaffenberger and Pritchett, 2020b, 2021) and the literature on estimating the immediate costs of instructional disruptions (Neidhöfer et al., 2021). The integrated framework includes explicit modelling of continuous parental investments, filling a gap in the literature related to the Potential Pedagogical Function and other explicit models of learning progression and acquisition. In the same way, the model considers the role of economic resources as part of the resources employed by parents to mitigate the effects of a temporary shock in instruction., expanding the notion of attenuation capacity developed by Neidhöfer et al. (2021). Finally, I take this framework to the data to estimate the potential effects of the instructional disruption caused by the COVID-19 pandemic in Mexico. The estimates suggest that, for the Mexican cohort affected by the instructional disruption, the potential persistent loss in learning with respect to the counterfactual lies on average between $20 \%$ and $90 \%$ of the learning acquired during a usual school year, depending on the effectiveness of the remote learning policies implemented during 2020 and 2021. These results already consider the mitigating role of parental investments. Furthermore, my results suggest substantial variation between inhabitants from different regions of the country and inside inhabitants of the same region, being the South of the country the region where the losses are the largest.
\end{abstract}

JEL-Classification: I24, I25, I28, J24, O15

Keywords: Educational disruptions, Learning progression, Education, Mexico, COVID-19, Persistence

*I deeply appreciate the comments made by Miles Corak, Jonathan Conning, Audrey Light, Roberto VélezGrajales, Nuria Rodríguez-Planas, Wim Vijverberg and the participants of the Dissertation Seminar of the PhD in Economics at The Graduate Center, CUNY, the participants of the Stone Center Multidisciplinary Seminar Series, the participants of the Seminario del Programa Universitario de Estudios sobre Educación Superior, and the El Colegio de México Economics Seminar to a previous draft of this document. I will also like to thank Mariana Tello de Jaray for her excellent research assistance. All remaining errors are my own.

${ }^{\dagger} \mathrm{PhD}$ Candidate in Economics; The Graduate Center, CUNY. lmonroygomezfranco@gradcenter.cuny.edu 


\section{Introduction}

A classic problem for policymakers is the lack of information on the long-run effects of any shock. This is particularly true for processes in which their outcomes are observed only after long periods, an example of which is the learning process. This lack of information makes the implementation of measures to attenuate the effects of the shock more complex to the policymaker, as neither the magnitude nor the characteristics of those impacted are apparent at the time of the shock. In this paper, I integrate and expand previous work on learning progression and educational disruptions by Kaffenberger and Pritchett (2020b, 2021) and Neidhöfer et al. (2021) into a unified model of learning progression, parental investments and instruction interruptions. This integration allows me to disaggregate the impacts of an instructional disruption into its immediate effects and its cumulative effects of learning, highlighting the role played by parental resources (and its distribution) in attenuating those effects. Furthermore, this approach allows to expand the calculation of the costs of an educational disruption proposed by Neidhöfer et al. (2021) to consider the immediate costs and the cumulative ones.

However, in contrast with Kaffenberger and Pritchett (2020b, 2021) and Neidhöfer et al. (2021), I model parental interventions as constantly occurring throughout the learning trajectory of children following recent research on the economics of parenting (Doepke et al., 2019). The integrated framework also allows me to analyse how different policy interventions can interact with parental interventions to attenuate the effects of the disruptions. Thus, the model provides a framework for the policymaker to opportunely assess the effects of a shock and the policy alternatives available to her.

The model presented in this paper represents an alternative to the traditional approach to modelling learning acquisition in economics, represented by Cunha et al. (2010). Although both models focus on learning accumulation instead of schooling, they take very different approaches to the subject. In the case of Cunha et al. (2010), the focus of the model is at the level of the individual, requiring vast information regarding non-cognitive and cognitive skills in the relevant population in order to be calibrated for the estimation of optimal interventions. This reduces the approach's applicability to contexts where data is more scarce, or it is only available at an aggregated level. In contrast, the model presented here requires less information regarding the individual skills while still being able to replicate the observed patterns in learning accumulation and being suitable to inform about the impacts of different interventions. These characteristics make it relevant for the case of developing countries where data constraints limit the application of formal modelling to inform the policymaking process about the long-run effects of interventions. 
A growing empirical literature has documented the medium and long-run effects of an instructional disruption on educational attainment, standardised test scores and labour market outcomes. The papers in this literature find that an instructional disruption translates into lower educational attainment, scores or earnings in the absence of private or public attenuation measures. These effects are observed both when the cause of the instructional interruption is a major societal disruption (for example, the Second World War (Ichino and Winter-Ebmer, 2004) , the Chinese Cultural Revolution (Meng and Zhao, 2021), or a natural disaster(Andrabi et al., 2021; Sacerdote, 2012) and less socially disruptive causes, like a teacher strike (Jaume and Willén, 2019; Belot and Webbink, 2010) or an abnormal frequency of snowing days (Marcotte and Hemelt, 2008).

Due to data restrictions, the studies that focus on the effects of educational disruptions after five years of the event tend to rely on formal measures of schooling, such as enrollment and years of education as a proxy of the human capital or learning stock of the children affected by the shock (see, for instance, Ichino and Winter-Ebmer (2004); Belot and Webbink (2010); Meng and Zhao (2021)). A recent series of studies on the relationship between learning acquisition and schooling progression questions this assumption. Evidence from Indonesia (Beatty et al., 2021), Rwanda (Crawfurd, 2021), multiple African countries (Pritchett and Sandefur, 2020; Kaffenberger and Pritchett, 2020a) and Pakistan (Bau et al., 2021) indicates that the increase in the average number of school years in those countries has not been matched by an increase in the stock of learning of children as measured by standardised tests. Thus, this evidence suggests that the impacts of a transitory instructional disruption on the human capital of those affected are not necessarily captured in the schooling dimension, and thus they should be modelled in the learning dimension or in outcomes linked to the stock of learning, such as labour earnings as Jaume and Willén (2019) do.

The decoupling between learning and school progression is also present in the analyses by Andrabi et al. (2021), and Sacerdote (2012) on the role of responses to natural disasters on the persistence of the effects of an instructional interruption. Andrabi et al. (2021) analyse the case of the 2005 earthquake in Kashmir, Pakistan, while Sacerdote (2012) studies the effects of Hurricane Katrina in New Orleans, USA. In both cases, the authors study the effects of the natural disaster on learning (test scores) and a measure of formal educational progression (school enrollment). However, the type of response by the public sector and households differs. In Kashmir, households affected by the earthquake received a cash transfer that represented, on average, $150 \%$ of their monthly consumption. Children affected by the hurricane relocated to school districts with better quality schools regarding their average score in standardised tests in the New Orleans case. In both studies, the authors do not find any effect of the disruption 
and compensatory measure in their measure of formal schooling, but they find an effect in the children's performance in standardised tests. Sacerdote (2012) finds that after an initial decline, four years after the relocation due to the hurricane, the test scores of the children who changed residence improved regarding their pre-Katrina score compared with those who did not move. In contrast, Andrabi et al. (2021) find that the score of those affected by the earthquake remained below those unaffected four years after the earthquake.

The results by Andrabi et al. (2021); Sacerdote (2012) highlight the importance of considering the effects of an instructional interruption in terms of learning and not only schooling. They also show that the short-run impacts are not necessarily representative of the long-run ones, which are influenced by the responses by households and policymakers. The rest of the paper goes as follows. In the following section, I describe the formal model used to characterise how the instructional process affects learning acquisition. Next, I describe the methodology employed to measure the short-run losses in learning due to an instructional disruption and how these losses can be introduced into the learning acquisition model to estimate the cumulative effects of the disruption. In the fourth section of this paper, I describe the data, and the calibration of the model used to estimate the potential losses caused by COVID-19 in Mexico. Afterwards, I present the application results and conclude with some final remarks and future avenues of research.

\section{Instructional processes and learning acquisition.}

Modelling the impacts of an instruction disruption on learning requires a model of how educational instruction affects learning acquisition during an educational career. Identifying the impact of instruction on learning has been the subject of interest of a vast literature on Educational Production Functions. (EPF). EPF, as their name indicates, consider learning as the output of a multi-input production process, establishing the marginal contribution of each of the inputs to the learning acquired by the student ${ }^{1}$.

The most common formulations of the EPF consider four groups of variables as determining the stock of learning $\left(A_{i t}\right)$ that a child i has accumulated up to moment t: family background factors $\left(B_{i t}\right)$, peer factors $\left(P_{i t}\right)$, school-related factors $\left(S_{i t}\right)$, and the innate affinities and abilities of each child $\left(I_{i t}\right)$. The stock of each of these factors determines the stock of learning of person

\footnotetext{
${ }^{1}$ The origin of the Educational Production Functions literature is the Coleman Report (Coleman et al., 1966) commissioned by the U.S. Congress to identify the association between different elements of a student background and her performance in school. For a review of the early literature see Bowles (1970); Hanushek (1979) and for more recent studies Hanushek $(2002,2010)$; Todd and Wolpin (2003)
} 
$i$ up to moment $t$. Formally, this can be expressed in a general form as follows:

$$
A_{i}(t)=f\left(B_{i}(t), P_{i}(t), S_{i}(t), I_{i}(t)\right)
$$

From equation 1 it is possible to derive the formulation corresponding to the learning gains occurred between two periods. Equation 1 implies that any gains in learning between $t$ and $t-1$ occur due to a change in the input stocks. Let $\Delta$ represent the change in a given variable between $t$ and $t-1$, this can be formally expressed as follows:

$$
\Delta A_{i}=f\left(\Delta B_{i}, \Delta P_{i}, \Delta S_{i}, \Delta N_{i}\right)
$$

From equation 1 we know that the learning observed in the previous period $\left(a_{i, t-1}\right)$ is a sufficient statistic of the history of values of the inputs, transformed according to the learning technology $f(\cdot)$ (Todd and Wolpin, 2003). Thus, the level of learning observed at time t, namely $a_{i, t}$ can be expressed as the sum of the current values of the inputs $\left(B_{i t}, P_{i t}, S_{i t}, I_{i t}\right)$, plus the learning observed in the previous period $a_{i, t-1}$, which represents the learning stock up until period $t-1$ This is the value-added formulation of an Educational Production Function.

$$
a_{i, t}=f\left(B_{i t}, P_{i t}, S_{i t}, I_{i t}\right)+a_{i, t-1}
$$

A limitation of EPFs is that they do not provide an explicit model of the mechanisms behind learning accumulation. Specifically, they do not specify the different mechanisms through which each input influences learning acquisition, nor how those mechanisms might change in the face of a temporary shock. A way to address this limitation of EPF is through a structured model of learning accumulation that explicitly represents these mechanisms. The Potential Pedagogical Function proposed by Kaffenberger and Pritchett (2021, 2020b) is such a model.

The Potential Pedagogical Function (PPF) models the interplay between the expected process of learning accumulation implied in school curricula and the preconditions of the students that 
interact with it. By explicitly modelling the relationships between the different inputs of the learning production process, the PPF allows the analysis of the effects of changes in those relationships and the level of the inputs on the learning accumulation process. This property makes it an ideal starting point for the construction of a model of the effects of instructional interruptions.

Following Kaffenberger and Pritchett (2020b, 2021), the first element of the PPF is the learning profile (LP) implied by the school curriculum of a specific school grade. The learning profile represents the learning gains (in this case, in terms of points in a standardised test) that a student is expected to acquire by attending school grade $\mathrm{G}$, and it is a function of the learning stock accumulated by students up until the end of grade G-1. It is defined by a coverage width $(\mathrm{w})$, the median of prerequisite knowledge $\left(\pi^{G}\right)$, the minimum and maximum expected learning gains $\left(z_{\min }, z_{\max }\right)$, and the learning gradient in school grade $\mathrm{G}(v)$. The educational authorities define all these elements in the curriculum for a specific school grade.

The coverage width of school grade $\mathrm{G}(w)$ represents the domain upon which the learning profile is effective. In other words, it is the set of values of the learning stock upon which the attendance to school grade $\mathrm{G}$ will lead to students learning something new. The width is centred at a specific value of previous knowledge $\left(\pi^{G}\right)$, which represents the learning stock at the end of school grade G-1 of the median student in the school system. The minimum $z_{\min }$ (maximum $z_{\text {max }}$ ) expected learning gains correspond to the learning gains that a student with the minimum (maximum) amount of previous knowledge on the subject will obtain during school grade G. The gradient indicates the gains above the minimum learning gains that a student with a learning stock above the minimum will gain during the school grade G. It is defined by the combination of the width, minimum, and maximum learning gains define the learning gradient of the school grade $(v)$ as follows:

$$
v=\frac{z_{\max }-z_{\min }}{w}
$$

All these elements, along with the learning stock of students at G-1, $A_{i, G-1}$, define the learning profile, and consequently the expected learning gains according to the curricula during grade $\mathrm{G}\left(a_{i, G}^{G}\right)$ as follows:

$$
L P\left(w, z, v, \pi^{G}\right)=a_{i, G}=z_{\min }+v\left(A_{i, G-1}-\left(\pi^{G}-\frac{w}{2}\right)\right)
$$


Equation 5 is equivalent to an EPF in its value-added form (equation 3) from the policymaker's point of view that designed the curricula of school grade G. However; it is not necessarily equal to the observed EPF. As the evidence on the decoupling between schooling learning gains summarised in the previous section indicates, the EPF implied in the curricula of school grade $\mathrm{G}$ is not necessarily the one that is effective for all students attending that school grade.

The PPF formalises this empirical insight by establishing that only the children with a stock of knowledge in the domain of the learning profile (equation 5) will gain any learning from attending school grade G. From the definition of the learning profile for grade $\mathrm{G}$ we know that its domain is the set $A_{i, G-1} \in\left[\pi^{G}-\frac{w}{2}, \pi^{G}+\frac{w}{2}\right]$, which implies that children with a stock of knowledge $A_{i, G-1}<\pi^{G}-\frac{w}{2}$ or $A_{i, G-1}>\pi^{G}+\frac{w}{2}$ will not learn anything while attending school grade G. Informally, this means that students without the prerequisites for course $G$ will not learn anything if they were to attend and complete grade $G$, while those with a knowledge level above that of the contents of grade $G$ will also not learn anything from attending grade $G$.

With these elements, it is possible to define the PPF as a function from the learning stocks of children at G-1 to the effective learning gains at the end of $\mathrm{G}\left(F: A_{i, G-1} \rightarrow a_{i, G}\right)$ with the following form.

$$
\operatorname{PPF}\left(L P(\cdot), A_{i, G-1}\right)=a_{i, G}= \begin{cases}0 & \text { if } A_{i, G-1}<\pi^{G}-\frac{w}{2} \\ z_{\min }+v\left(A_{i, G-1}-\left(\pi^{G}-\frac{w}{2}\right)\right) & \text { if } \pi^{G}-\frac{w}{2} \leq A_{i, G-1} \leq \pi^{G}+\frac{w}{2} \\ 0 & \text { if } A_{i, G-1}>\pi^{G}+\frac{w}{2}\end{cases}
$$

The PPF describes the effective EPF of school grade $G$ in which the learning gains experienced by a student during a school grade depend on the learning stock accumulated up to the beginning of that grade. The non-linear gains allow the model to reproduce the decoupling between school and learning progression observed in the empirical data.

So far, this model only characterises the learning gains from a school year. In order to replicate the process of learning accumulation through a school career, it is necessary to include the progression in the centre of the learning profiles of different school grades. Kaffenberger 
and Pritchett $(2021,2020 \mathrm{~b})$ propose doing so by including a "shift" parameter $\rho$ that represents the expected learning gains of the median student according to the school curricula. Formally, this implies that from school grade $G$ to school grade $G+1$, the boundaries of the width of the learning profile increase according to the following equations:

$$
\begin{aligned}
& \left(\pi^{G}+\rho\right)-\frac{w}{2}=\pi^{G+1}-\frac{w}{2} \\
& \left(\pi^{G}+\rho\right)+\frac{w}{2}=\pi^{G+1}+\frac{w}{2}
\end{aligned}
$$

By modelling learning progression in this way, the PPF proposed by Kaffenberger and Pritchett $(2021,2020 b)$ implies that the only input relevant to learning accumulation is schooling. In the context of EPFs, Todd and Wolpin (2003) suggest that the score of a standardised test at the end of a school grade is a sufficient statistic of the learning attained during the school grade. That is, the test score $a_{i, G}$ summarises all the relevant information on the educational inputs invested during school grade $\mathrm{G}$ and the previous stock of learning of student $i$. This property, however, no longer holds in the case of a structured model such as the PPF. That is because a structured model seeks to explicitly model the mechanisms through which each input influences the outcome variable. This implies that non-modelled mechanisms are assumed to be non-existent. Thus, the description of learning accumulation in the PPF, as proposed by Kaffenberger and Pritchett (2021, 2020b), ignores the role of parental investments during a child's academic career, contradicting much of the literature on parenting and human capital investments (Doepke et al., 2019).

I supplement this omission in the basic PPF model by explicitly modelling parental investments in their children's human capital, subject to the resource constraint of the parental household in the spirit of Ben-Porath (1967); Leibowitz (1974) and Todd and Wolpin (2003). Specifically, I model parental investments as a compensatory measure to guarantee that a child remains in the domain of the learning profile of the school grade she is attending, thus replicating the empirical finding that parental investments are complements to schooling (Heckman and Mosso, 2014).

In this framework, the parents' objective is to guarantee that their child has a knowledge stock sufficiently high enough to be in the domain of the learning profile of the school grade in which the child is enrolled. Their restriction is the amount of educational and economic 
resources available to them.

This restriction can be expressed as the weighted sum of the educational and economic resources of the household. Let $e_{i}$ be the educational attainment in school years of the parents of child $\mathrm{i}$, and $w_{i}$ the economic resources in the household of child i. Then, the total amount of educational resources of household i can be expressed in relative terms as the ratio between the observed attainment $e_{i}$ and the maximum attainment in the population, $\max (e)$. Similarly, the total amount of economic resources in the household expressed in relative terms is the ratio of the difference between the maximum amount of resources $\max (w)$ and the amount of household $i, w_{i}$ and the range of the economic resource distribution, $\max (w)-\min (w)$. Then, the total amount of resources in household $\mathrm{i}$ is defined as follows.

$$
\beta_{i}=\theta \frac{e_{i}}{\max (e)}+(1-\theta)\left[1-\frac{\left|\max (w)-w_{i}\right|}{|\max (w)-\min (w)|}\right]
$$

Equation 9 is similar to what Neidhöfer et al. (2021) consider the attenuation capacity of households. However, a major difference between equation 9 and Neidhöfer et al. (2021) is that the former considers both educational and economic resources, following the literature on the determinants of parental investments (Heckman and Mosso, 2014; Prix and Erola, 2017). In contrast, Neidhöfer et al. (2021) only consider the role played by educational resources.

Next, define $A_{i, G-1}^{*}$ as the stock of learning of child $i$ before the beginning of grade G. From equation 1, this stock is a function of schooling, parental investments, peers and innate skills. Assuming that peer effects occur in the environments where schooling and parental investments take place and that innate ability is predetermined, the reduced form of $A_{i, G-1}^{*}$ is given by:

$$
A_{i, G-1}^{*}=f\left(B_{i, t-1}, S_{i, t-1}\right)
$$

Given that parents seek to minimise the distance between the knowledge stock of their children and the median knowledge stock in the domain of the learning profile of grade $G$, the optimal investment they have to perform is equivalent to the distance between $\pi^{G}$ and the stock of knowledge at the end of grade $G-1, A_{i, G-1}$ penalised by the number of resources available to the household. Thus, the stock of knowledge at the beginning of grade $\mathrm{G}$ will be given by: 


$$
A_{i, G-1}^{*}=A_{i, G-1}+\beta\left|\pi^{G}-A_{i, G-1}\right|
$$

Redefining equation 8 to be in terms of the knowledge stock before the start of grade $\mathrm{G}$, $A_{i, G-1}^{*}$, gives the following PPF, in which both the role of schooling and parental investments are explicitly modelled:

$$
P P F\left(L P(\cdot), A_{i, G-1}^{*}\right)=a_{i, G}= \begin{cases}0 & \text { if } A_{i, G-1}^{*}<\pi^{G}-\frac{w}{2} \\ z_{m i n}+v\left(A_{i, G-1}^{*}-\left(\pi^{G}-\frac{w}{2}\right)\right) & \text { if } \pi^{G}-\frac{w}{2} \leq A_{i, G-1}^{*} \leq \pi^{G}+\frac{w}{2} \\ 0 & \text { if } A_{i, G-1}^{*}>\pi^{G}+\frac{w}{2}\end{cases}
$$

Finally, the accumulation of the learning for child $i$ is given by the following equation.

$$
A_{i, G}=A_{i, G-1}^{*}+a_{i, G}
$$

The last parameter in the model is the dropout rate. Following Kaffenberger and Pritchett (2021, 2020b), the dropout rate is modelled as a function of the knowledge stock of the children. Specifically, the assumption is that the lower tail of the distribution of the knowledge stock drops out of school at a rate consistent with the observed dropout rates in the educational system. Let $\phi^{G}$ be the grade-specific cut-off value of the knowledge stock distribution below which students drop out., then the dropout function will be defined as

$$
q\left(A_{i}\right)= \begin{cases}1 & \text { if } A_{i} \leq \phi^{G} \\ 0 & \text { if } A_{i}>\phi^{G}\end{cases}
$$

Together, equations 8, 9,11,12, 13 and 14 form the learning progression model used in the rest of the paper. 


\section{Estimating the costs of an instructional disruption}

In general terms, an educational disruption can have two types of costs: immediate and cumulative costs. The first set corresponds to the share of a school year lost because in-person instruction was suspended due to the occurrence of an external event (the underlying cause of the disruption). This share is equivalent to the share of the learning of a school year lost due to the in-person class suspension. The cumulative costs are those associated with the lags in the learning progression that a student might experience at further stages of her academic career due to the disruption of in-person instruction. This second set of costs occurs due to the immediate costs that might displace the student from the domain of the learning profile of the school grade she is attending. This would imply that the student fails to obtain the expected learning gains from that course and starts to lag behind the learning profile of the subsequent school grades.

In the following subsections, I delve into the characterisation of both types of costs.

\section{Estimating the immediate learning cost}

To estimate the immediate costs, I generalise the approach proposed by Neidhöfer et al. (2021). This approach considers three significant components of the immediate costs of a learning disruption faced by a child. The first two components are defined at the lowest geographical level of aggregation for which data is available. The third allows translating the costs from the aggregate level to the individual level.

The first component is the gross cost of the disruption, $\mathrm{O}$. These costs are the sum of the share of the school year during which in-person classes did not occur, $\frac{d}{D}$, and the days lost due to the incidence of the underlying cause of the instructional interruption, expressed as a share of the school year. This second component is the product of the days lost due to the underlying cause of the disruption, $\lambda$, and the probability of being affected by it, $\Omega$. Thus, the expected value of the gross costs of the disruption is given by:

$$
E(O)=\frac{d}{D}+\frac{\lambda \times \Omega}{D}
$$

The second component of the immediate costs is the government's attenuation measures to diminish the impact of the instructional interruption Z. Following Neidhöfer et al. (2021), I model 
this as the product between their effectiveness in substituting a day of in-person instruction $\gamma$, and the probability of access to these attenuation measures, $\theta$. I express these measures in terms of the share of the school year in which in-person instruction did not occur. The following equation gives the expected value of these public attenuation measures:

$$
E(Z)=\frac{d}{D}(\gamma \times \theta)
$$

With the gross immediate costs and the public attenuation measures, it is possible to construct the expected value of the net immediate costs faced by each household, $k_{r}$ as follows

$$
E\left(k_{r}\right)=E(O)-E(Z)=\frac{d+\lambda \times \Omega-d(\gamma \times \theta)}{D}
$$

The immediate net costs are assumed to be homogeneous across the region of analysis. What produces differences at the individual level is the attenuation capacity of households. This is the household's capacity to diminish the effect of the immediate net costs on the children's learning process. Neidhöfer et al. (2021) define it as a negative function of the educational resources of the parents of the children. However, their formulation leaves aside the role of economic resources as enabling households to diminish the effects of a shock on a student's learning process. Following the formulation of total resources of a household in equation 9, in equation 18, I define the attenuation capacity of the household as a negative function of the total resources in the household:

$$
1-\beta_{i}=1-\left(\theta \frac{e_{i}}{\max (e)}+(1-\theta)\left[1-\frac{\left|\max (w)-w_{i}\right|}{|\max (w)-\min (w)|}\right]\right)
$$

The effective learning cost experienced by child $i, C_{i}$, will depend on the attenuation capacity of her household and the immediate net costs experienced in the region. I define the effective learning cost as the share of the learning gains from a school grade lost due to instructional disruption. Formally the expected value of the effective learning costs is given by : 


$$
E\left[C_{i}\right]=(1-\beta) \times E\left(k_{r}\right)=(1-\beta) \times \frac{d+\lambda \times \Omega-d(\gamma \times \theta)}{D}
$$

Equation 19 represents the immediate loss of learning experienced by children i in terms of the share of learning from a school grade that the students do not obtain due to the instructional disruption. This cost is included in the model of learning accumulation developed in the previous section to calculate the cumulative cost of the disruption. This calculation is explained in the following subsection.

\section{Estimating the cumulative learning costs of an instructional disruption}

The first step to estimate the cumulative effects of a transitory instructional disruption, is to introduce the immediate costs into the model of learning accumulation. Assuming that the transitory shock occurred when child $i$ attended school grade $G$, the accumulation of learning described in equation 12 will be affected by costs $E\left[C_{i}\right]$. This means that the stock of learning at the end of grade $G$ will be given by:

$$
A_{i, G}=A_{i, G-1}^{*}+\left(1-E\left[C_{i}\right]\right) a_{i, G}
$$

Using equation 20 as the accumulation rule at grade $\mathrm{G}$ and afterwards employing the model of learning progression defined by equations 8, 9, 11, 12, 13 and 14 for the rest of the school grade allows simulating the learning trajectory under the effects of the instructional shock. If the end of the learning trajectory is grade $T$, then the stock of learning resulting from this trajectory for child $i$ will be $\widehat{A_{i, T}}$. This is the stock of learning under the effects of the interruption. The model defined by equations 8, 9, 11, 12, 13 and 14 can then be used to construct a counterfactual trajectory in which the shock never took place. The resulting learning stock is denoted by $A_{i, T}$.

Similarly, it is possible to define a counterfactual trajectory that considers the learning progression expected by the educational system. Equation 8 define this progression through the parameter $\rho$, which defines the learning gain for each school grade implicit in the progression of the school curricula. Thus, for T school grades the stock of learning accumulated at the end of this learning progression will be defined by 


$$
A_{i, T}^{-}=T \rho
$$

With these three learning stocks, it is possible to estimate the cumulative learning costs of an instructional disruption. The effective cumulative learning cost (ECC) is estimated as the difference between the learning stock at $T$ of the trajectory without a shock, $A_{i, T}$, and the learning stock of the trajectory that considers the effect of the shock, $\widehat{A_{i, T}}$. This difference is expressed in terms of the learning progression from one grade to the next one implied in the school system curricula $\rho$. Thus, the difference is measured as the years of learning progression lost due to the shock with respect to a scenario without a shock. Formally,

$$
E C C=\frac{\widehat{A_{i, T}}-A_{i, T}}{\rho}
$$

It is also possible to estimate the cumulative cost with respect to the median progression implied by the school system curricula (SCC). The SCC is the difference between the learning stock at $\mathrm{T}$ of the trajectory that considers the effect of the instructional shock and the learning stock accumulated under the learning progression of the system given by $\rho$. As before, the difference is expressed in terms of $\rho$, which allows interpreting the result as the years of learning progression lost due to the shock with respect to the expected progression of the system. Formally, this is

$$
S C C=\frac{\widehat{A_{i, T}}-\widehat{A_{i, T}}}{\rho}
$$

In the following section, I provide an empirical illustration of the model for estimating the immediate and cumulative costs of the instructional disruption in Mexico due to the COVID-19 Pandemic. The empirical illustration seeks to highlight the role of the additions to the basic model and the robustness of the estimations to changes in several key parameters. 


\section{An application: Mexican children during the COVID-19 Pandemic}

\section{Data and Calibration of the Learning Accumulation Model.}

The first step in bringing the model described by equations $8,9,11,12,13$ and 14 to produce an estimate of the potential learning effects of the COVID-19 pandemic in Mexico is to calibrate the learning progression model to the observed data on learning acquisition in the country. For this exercise and following previous exercises (Kaffenberger and Pritchett, 2020b, 2021), I use as a measure of learning acquisition the math scores of a nationally implemented standardised test. For this exercise, I use the average test score and standard deviation of the 2017 math component of the National Plan for the Evaluation of Learnings (Programa Nacional para la Evaluación de los Aprendizajes, PLANEA in Spanish) for students in ninth grade. This test has information at both the national and regional level, allowing me to calibrate a PPF for each one of the regions of the country ${ }^{2}$. In addition, due to institutional changes in the country, the test from 2017 is the most recent information on math learning for students in ninth grade.

The model has four parameters to be calibrated: $\rho, z_{\min }, z_{\max }$ and $w$. For the value of $w$, I follow Kaffenberger and Pritchett (2020b), who assume that the learning profile covers all students enrolled in the system at the beginning of their educational trajectory. This assumption, although extreme, implies overestimating the coverage of the learning profile, thus implying an underestimation of the impacts of an instructional disruption. This leaves three parameters to be calibrated: $\rho, z_{\min }$, and $z_{\max }$

In the Mexican context, the parameter $\rho$ is defined at the national level, as the federal ministry of education determines the school curricula for primary and secondary education. Hence, to obtain its value, I calibrate a PPF at the national model by selecting the values of $\rho, z_{\min }$, and $z_{\max }$ that produce a learning trajectory that at the end of ninth grade produces the values of the average score and standard deviation as close as possible to those observed in the standardised test. With this value of $\rho$, I calibrate the values of, $z_{\min }$, and $z_{\max }$ for each region using the same methodology as before: selecting the values of $z_{\min }$, and $z_{\max }$ that

\footnotetext{
${ }^{2}$ Given the data restrictions from the Espinosa Rugarcia Social Mobility in Mexico Survey 2017 I am restricted to only consider five aggregate regions of the country composed in the following way: the North region consists of Baja California, Sonora, Chihuahua, Coahuila, Nuevo León and Tamaulipas; North West consists of Baja California Sur, Sinaloa, Nayarit, Durango and Zacatecas; the Center North region is form by Jalisco, Aguascalientes, Colima, Michoacán and San Luis Potosí; the Center region is formed by Guanajuato, Querétaro, Hidalgo, Estado de México, ; Mexico City, Morelos, Tlaxcala, and Puebla; the South region is formed by Guerrero, Oaxaca, Chiapas, Veracruz, Tabasco, Campeche, Yucatán and Quintana Roo.
} 
produce a learning trajectory that in ninth grade replicates as close as possible the observed average regional mean score and the standard deviation of the regional scores. Table 1 shows the calibrated parameter values and the comparison between the observed scores and those derived from the calibrated models.

Table 1. Parameter values for the Mexican case

\begin{tabular}{cccccc}
\hline & North & North West & Center North & Center & South \\
\hline $\begin{array}{c}\text { Average math score in PLANEA 2017 } \\
\text { (Total sample) }\end{array}$ & 492 & 494 & 513 & 511 & 483 \\
$\begin{array}{c}\text { Average math score } \\
\text { (Model) }\end{array}$ & 483.824 & 492.5117 & 497.2913 & 503.016 & 466.338 \\
$w$ & $(0.5367)$ & $(0.7484$ & $(0.4891)$ & $(0.4660)$ & $(1.2817)$ \\
$z_{\min }$ & 153 & 153 & 153 & 153 & 153 \\
$z_{\max }$ & 37.7 & 37.7 & 38.4 & 38.4 & 36.5 \\
$\rho$ & 71.63 & 71.63 & 72.96 & 72.96 & 69.35 \\
$v$ & 54 & 54 & 54 & 54 & 54 \\
Initial distribution & 0.2218 & 0.2218 & 0.2259 & 0.2259 & 0.2147 \\
& $\mathrm{~N}(0,20)$ & $\mathrm{N}(0,20)$ & $\mathrm{N}(0,20)$ & $\mathrm{N}(0,20)$ & $\mathrm{N}(0,20)$ \\
\hline
\end{tabular}

To calculate the economic and educational resources of the household (equation 9), I use the data from the Espinosa Rugarcia Social Mobility in Mexico Survey 2017 (ESRU-EMOVI 2017). This survey is designed to measure social mobility in Mexico and its regions and consequently has extensive information about the Mexican population's living conditions and parental characteristics. Furthermore, the survey is representative at the national and regional level for the population between 25 and 64 years old, recovering information about the conditions of the households they inhabited when 14 years old. However, I am only interested in the information of the youngest cohort (25 to 30 years old) as the conditions of their households of origin are closest to the characteristics of the current Mexican households. Consequently, the sample employed diminishes from 17,665 to 2,474 observations.

It is important to note that although the conditions of these households are not necessarily equivalent to the conditions of current Mexican households, they represent a sample of households of which ample information about conditions of origin is available and that does not suffer from co-residence bias. Table 2 shows the sample's composition in terms of sex, indigenous status, urban residence, and the years of school attainment of the respondent and both parents.

To measure the educational resources in the household, I use the average years of education of both parents or those of the present parent in single-parent households. In this, my measure 
Table 2. Descriptive Statistics of ESRU-EMOVI 2017.

\begin{tabular}{ccccccc}
\hline Variable & National & North & North West & Center North & Center & South \\
\hline Years of school of interviewee & 11.8453 & 11.4828 & 12.2753 & 11.6716 & 12.5643 & 10.9050 \\
(Regional mean) & $(0.1291)$ & $(0.2009)$ & $(0.2578)$ & $(0.2989)$ & $(0.2396)$ & $(0.3074)$ \\
Years of school of the father & 7.5955 & 8.1953 & 6.7974 & 7.4127 & 8.8788 & 5.4875 \\
(Regional mean) & $(0.2115)$ & $(0.2568)$ & $(0.3377)$ & $(0.3669)$ & $(0.4235)$ & $(0.3393)$ \\
Years of school of the mother & 7.2009 & 8.1953 & 7.1173 & 7.2323 & 8.2746 & 5.0322 \\
(Regional mean) & $(0.1896)$ & $(0.2473)$ & $(0.3714)$ & $(0.3350)$ & $(0.4236)$ & $(0.3308)$ \\
Female population & 0.5219 & 0.5307 & 0.5139 & 0.5217 & 0.5160 & 0.5284 \\
(Share of regional population) & $(0.0141)$ & $(0.0242)$ & $(0.0321)$ & $(0.0352)$ & $(0.0273)$ & $(0.0264)$ \\
Urban community of origin & 0.7297 & 0.8955 & 0.6048 & 0.7135 & 0.8374 & 0.4953 \\
(Share of regional population & $(0.0327)$ & $(0.0244)$ & $(0.0566)$ & $(0.0449)$ & $(0.0298)$ & $(0.0411)$ \\
Indigenous population & 0.1085 & 0.0525 & 0.0254 & 0.0641 & 0.0656 & 0.2618 \\
(Share of regional population) & $(0.0123)$ & $(0.0161)$ & $(0.0146)$ & $(0.0169)$ & $(0.0149)$ & $(0.0326)$ \\
Regional population & & 0.1588 & 0.0673 & 0.1310 & 0.4137 & 0.2292 \\
(Share of national population) & & $(0.0184)$ & $(0.0098)$ & $(0.0163)$ & $(0.0361)$ & $(0.0213)$ \\
\hline
\end{tabular}

Notes: Data from ESRU-EMOVI 2017 for respondents between 25 and 30 years old. Standard errors in parenthesis.

of educational resources is the same as that employed by Neidhöfer et al. (2021). In the case of economic resources, I use a household asset index to measure them. Household asset indices have been employed in the development literature for analysis regarding the distribution of economic resources when other variables such as income are not available (see Filmer and Pritchett (2001); McKenzie (2005); Wittenberg and Leibbrandt (2017); Poirier et al. (2020)). In this case, as ESRU-EMOVI 2017 only records the ownership of an asset, I employ Multiple Correspondence Analysis (MCA) in the construction of the index. MCA uses relative frequencies across the binary variables considered to identify an underlying structure across the observations in terms of ownership of the assets. This underlying structure can produce a rank of the individuals in the sample according to the amount and type of assets they possess. Table 3 shows the assets employed in the construction of the index. With this data on educational and economic resources, I calculate equation 9 for all individuals in the sample.

Table 3. Binary variables for the parental household asset index.

\begin{tabular}{|l|l|}
\hline The household has access to the water supply & The household has a washing machine \\
\hline The household has an oven & The household has a landline telephone \\
\hline The household has a television & The household has a computer \\
\hline The household has a refrigerator & The household has a VHS \\
\hline The household has a microwave & The household has cable television \\
\hline The household owns a water heater & The household owns a vacuum cleaner \\
\hline $\begin{array}{l}\text { A member of the household owned } \\
\text { the housing facilities inhabited }\end{array}$ & A member of the household owns a car \\
\hline $\begin{array}{l}\text { A member of the household } \\
\text { has a bank account. }\end{array}$ & $\begin{array}{l}\text { A member of the household } \\
\text { owns a credit card. }\end{array}$ \\
\hline The household hires a domestic worker. & \\
\hline
\end{tabular}




\section{Calculation of the immediate costs}

The first step to calculate the immediate learning costs of the COVID-19 pandemic is to calculate the net costs as defined by equation 15 above. The net costs are composed of the direct costs COVID-19 in terms of days of in-person instruction lost and the effect of the attenuation measures deployed by the government. Moreover, the direct costs of COVID-19 consist of the school days under remote instruction, $d$, plus the expected value of the days lost due to the incidence and mortality of COVID-19. $\tau_{r}$, both expressed as a share of the days in a school year (190 in the Mexican case). Formally, this is

$$
E\left[O_{r}\right]=\frac{d+\tau_{r}}{D}
$$

In the case of the COVID-19 pandemic, the interruption of in-person instruction lasted the last third of the 2019-2020 school year (60 days) and the whole 2020-2021 school year. Thus, we calculate equation 22 for two school years, where in the first one $d=60$ and in the second one $d=190$. Let $P_{r}(s=1)$ be the probability of a household member being sick of COVID-19 and $P_{r}(m=1)$ be the probability that a household member died of COVID-19 for inhabitants of region $r$ and define $\tau^{s}=5$ as the number of school days lost due to sickness and $\tau^{m}=15$ the school days lost due to the mourning of the death of a household member. Then the expected value of the days lost due to the incidence and mortality of COVID-19 will be given by equation 25 for inhabitants of region $r$

$$
\tau_{r}=\tau^{s} \times P_{r}(s=1)+\tau^{m} \times P_{r}(m=1)
$$

In which the values for $\tau^{m}$ and $\tau^{s}$ are taken from Neidhöfer et al. (2021). The probabilities $P_{r}(s=1)$ and $P_{r}(m=1)$ are calculated with the data for the cumulative incidence and cumulative mortality of COVID-19 in region $\mathrm{r}$ from the official government records on the spread of COVID-19 in Mexico available at https://datos.covid-19. conacyt.mx/. I calculate the probabilities for each school year affected by the pandemic.

The second component of the net costs is the effect of the attenuation measures deployed by 
the government to reduce the impact of the instructional displacement on learning $(E(Z)$ in equation 16). In the case of the COVID-19 pandemic, the public attenuation measures taken by the government were two. The first was a program of remote instruction implemented through televised classes in which the course syllabus materials were covered (Ramírez-Raymundo et al., 2021). This was to act in tandem with the second component, which was the displacement of all instruction to a remote instruction model through internet-based platforms and telephone contact between parents, children and teachers (Diario Oficial de la Federación, 2020). However, the government did not expand the coverage of the internet, t.v. or telephone services.

A difficulty in modelling these two interventions is that there is no data on their effectiveness as substitutes for one day of in-person instruction. This limitation forces me to make different assumptions regarding their effectiveness. Let $\alpha$ be the share of in-person instruction that both interventions are able to substitute jointly and define $\phi$ and $\delta$ as the effectiveness parameter of each intervention ( $\delta$ for the televised transmissions, $\phi$ for the remote instruction model) such that $\phi+\delta=\alpha$. I simulate three cases $\alpha=0, \alpha=0.5$, and $\alpha=1$. As stated in equation 16, this substitutability capacity has to be weighted by the probability of access to the interventions by the relevant population, in this case, the population of region $r$. The relevant probabilities are, in this case, the probability that a household has access to a digital television, $\gamma_{r}$, the joint probability that a household has a computational device and internet access, $\kappa_{r}$, and the probability that the student remained in contact with their teachers $\lambda$. Thus, the formal expression of these attenuation policies is in equation 26 .

$$
E\left[Z_{r}\right]=\frac{d\left[\left(\delta \times \gamma_{r}\right)+\left(\psi \times \kappa_{r} \times j\right)\right]}{D}
$$

I calculate the probabilities $\gamma_{r}$ and $\kappa_{r}$ using information from the Mexican Population Census from 2020. At the same time, I calculate the probability $\lambda$ with the information from the ENCOVID-ED, a special telephone survey designed to gather information on the conditions under which remote learning took place (Instituto Nacional de Estadística y Geografía, 2021).

Substituting equations 24 and 26 into equation 19 provides the equation that I use to calculate the immediate costs of the pandemic as a share of a school year of learning. Formally, this is :

$$
E\left[C_{i}\right]=\left(1-\beta_{i}\right) \times \frac{d+\tau_{r}-d\left[\left(\delta \times \gamma_{r}\right)+\left(\psi \times \kappa_{r} \times \lambda\right)\right]}{D}
$$


Table 4 shows the average immediate costs of the pandemic at the national level under the three scenarios considered for the parameter $\alpha$. In the best case scenario, when $\alpha=1$, the average immediate cost at the national level represents a third of a school year of learning. In the worst case scenario, when $\alpha=0$, the costs represents a 0.9583 of a school year, where the potential maximum is of 1.3 years of learning. A first pattern observed in the data is that the assumption made about the remote instructional model's effectiveness in substituting in-person instruction plays an important role in the size and distribution of the cost. The larger the assumed effectiveness, the larger is the regional difference in the average immediate learning cost. For instance, if the remote instruction learning model is assumed to be a perfect substitute for in-person learning $(\alpha=1)$, the average immediate costs in the South represents 1.79 times the cost in the Center. On the other hand, if the substitutability is assumed to be null between those two modes of instruction $(\alpha=0)$, the cost in the South represents 1.18 times the cost in the Center.

Table 4. Average effective immediate cost in each scenario.

\begin{tabular}{cccc}
\hline \multirow{2}{*}{ Region } & $\begin{array}{c}\text { Average effective immediate cost } \\
(\alpha=1)\end{array}$ & $\begin{array}{c}\text { Average effective immediate cost } \\
(\alpha=0.5)\end{array}$ & $\begin{array}{c}\text { Average effective immediate cost } \\
(\alpha=0)\end{array}$ \\
\hline National & 0.2964 & 0.6273 & 0.9583 \\
& $(0.0052)$ & $(0.0066)$ & $0.0085)$ \\
North & 0.2208 & 0.5695 & $(0.9183$ \\
& $(0.0022)$ & $(0.0056)$ & 0.9741 \\
North West & 0.2957 & 0.6349 & $(0.0156)$ \\
& $(0.0047)$ & $(0.0102)$ & 0.9440 \\
Center North & 0.2619 & 0.6029 & $(0.0141)$ \\
& $(0.0039)$ & $(0.0090)$ & 0.9089 \\
Center & 0.2490 & 0.5789 & $(0.0140)$ \\
& $(0.0038)$ & $(0.0089)$ & 1.0726 \\
South & 0.4469 & 0.7598 & $(0.0152)$ \\
\hline
\end{tabular}

Note: Authors' calculations corresponding to equation 27. The effective immediate cost corresponds to the share of a school year of learning lost due to the transition to remote learning. Clustered standard errors in parenthesis. The clusters are defined at the primary sampling unit.

This pattern is a consequence of the interventions' effectiveness and the inequalities in the probability of access to them. As Campos-Vázquez and Monroy-Gómez-Franco (2016) and Delajara et al. (2021) show, the South region of the country is the region with lower social mobility rates in absolute terms and with higher levels of multidimensional poverty in Mexico. Consequently, the probability of access to the policy interventions is the smallest in the 
south of the country compared to other regions (see table A.3 in the appendix). Thus, as the effectiveness of a policy intervention increases, the greater the effect inequalities in access to them have in increasing or decreasing the cost of the instructional interruption. In other words, interventions that are highly effective in attenuating the cost of the instructional interruption increase the opportunity cost of not having access to them. This highlights an important factor in policy: even if the policy implemented is a perfect substitute for in-person instruction, gaps in access to the policy have to be closed for the policy to attenuate the learning cost of the disruption.

Table 4 also highlights another factor: the attenuation capacity of households can, on average, diminish the immediate cost of the disruption by $26 \%$ of the potential maximum. This is calculated as the share of the potential maximum effective immediate cost (1.3 of a school year of learning in this case) that the difference between the maximum possible loss and the average effective cost when $\alpha=0$ represents. The average maximum attenuation occurs in the Center region, where on average, households can reduce effective immediate cost by $30 \%$, whereas in the South, the private resources of the household only can attenuate $17 \%$ of the cost. This highlights the complementarity between public and private attenuation measures and the limits of a response to an instructional disruption that relies exclusively upon the households' resources.

Before proceeding to the estimation of the cumulative costs, an important question is how relevant is the inclusion of economic resources in the attenuation capacity of the household when estimating the immediate costs of an instructional cost. Table 5 shows the results of assigning different weights to the role of economic resources in the household's total resources (equation 8). I consider three scenarios: $\theta=1$, which is the scenario Neidhöfer et al. (2021) consider, $\theta=0.5$ which is my preferred estimation and $\theta=0$ which is a scenario where the only determinant of household resources are economic resources. Table 5 shows the results of this exercise for the different values of $\alpha$.

Table 5 shows that considering only the educational resources of the household as relevant $(\theta=1)$ produces the highest attenuation capacity and, consequently, the lowest effective immediate cost. In contrast, when only the economic resources of the household are considered relevant $(\theta=0)$, the result is the highest effective immediate costs. This suggests that although both types of resources are related, they do not entirely overlap. In particular, it suggests that the lower bound of the educational resources is higher than that of economic resources. This is consistent with the evidence regarding the evolution across generations of both educational attainment and economic resources in Mexico. Whereas there has been convergence in educational attainment, the same is not true regarding income or other types of economic resources. (de la Torre and Vélez-Grajales, 2016). Thus, it seems a better approach to include both types 
Table 5. Effect of different compositions of household resources

(National average effective immediate cost)

\begin{tabular}{cccc}
\hline & $\theta=1$ & $\theta=0.5$ & $\theta=0$ \\
\hline$\alpha=1$ & 0.2827 & 0.5979 & 0.9130 \\
& $(0.0055)$ & $(0.0080)$ & $(0.0112)$ \\
$\alpha=0.5$ & 0.2964 & 0.6273 & 0.9583 \\
& $(0.0052)$ & $(0.0066)$ & $(0.0084)$ \\
& & & \\
$\alpha=0$ & 0.3101 & 0.6568 & 1.0035 \\
& $(0.0052)$ & $(0.0061)$ & $(0.0076)$ \\
\hline
\end{tabular}

Author's calculations. $\theta=1$ corresponds to the case where household resources are composed exclusively of educational resources, while $\theta=0$ represents the case where household resources are composed only of economic resources. $\alpha=1$ corresponds to the case where the remote instruction is a perfect substitute of in person classes, $\alpha=0$ is the case where remote instruction has no effect on learning. The effective immediate cost corresponds to the share of a school year of learning lost due to the transition to remote learning.

of resources when possible.

For the estimation of the cumulative costs, I consider only the specification that considers $(\theta=0.5)$

\section{Calculation of the cumulative costs}

To estimate the potential cumulative costs of the COVID-19 pandemic, I simulate the process of learning accumulation in which the immediate costs estimated in equation 27 affects the learning acquired during sixth and seventh grade (sixth grade of primaria and first grade of secundaria in the terminology of the Mexican education system) and progresses up to ninth grade.

These simulations are done using the calibrated PPF for the Mexican case, varying the magnitude of the costs introduced in the sixth and seventh grades according to the student-specific costs estimated in the previous subsection (following equation 20). The counterfactual learning stock for student $i$ will be the mean value of the distribution produced by this simulated learning progression up to ninth grade. Then, the cumulative costs with respect a trajectory without pandemic are calculated following equation 22 and with respect to the school system expected trajectory using equation 23.

Table 7 shows two sets of results for the average cumulative costs (as defined by equation 20) 
Table 6. Average cumulative cost with respect to baseline scenario under different assumptions

\begin{tabular}{ccccccc}
\hline \multirow{2}{*}{ Region } & \multicolumn{2}{c}{ Without household compensating investment } & \multicolumn{4}{c}{ With household compensating investment } \\
\cline { 2 - 7 } & $\alpha=1$ & $\alpha=0.5$ & $\alpha=0$ & $\alpha=1$ & $\alpha=0.5$ & $\alpha=0$ \\
\hline \multirow{2}{*}{ National } & 0.9870 & 1.4479 & 2.0505 & 0.1871 & 0.4711 & 0.9040 \\
& $(0.0170)$ & $(0.0199)$ & $(0.0178)$ & $(0.0087)$ & $(0.0129)$ & $(0.0158)$ \\
\multirow{2}{*}{ North } & 0.8043 & 1.2391 & 1.8422 & 0.0773 & 0.1608 & 0.9178 \\
& $(0.0097)$ & $(0.0099)$ & $(0.0097)$ & $(0.0024)$ & $(0.0019)$ & $(0.0183)$ \\
\multirow{2}{*}{ North West } & 1.0624 & 1.4034 & 2.0195 & 0.2154 & 0.4065 & 0.7787 \\
& $(0.0133)$ & $(0.0177)$ & $(0.0147)$ & $(0.0069)$ & $(0.0064)$ & $(0.0154)$ \\
Center North & 0.7950 & 1.1504 & 1.7660 & 0.1803 & 0.3949 & 0.7575 \\
& $(0.0089)$ & $(0.0138)$ & $(0.0253)$ & $(0.0042)$ & $(0.0026)$ & $(0.0076)$ \\
Center & 0.7946 & 1.2542 & 1.8789 & 0.1270 & 0.4003 & 0.7601 \\
& $(0.0099)$ & $(0.0109)$ & $(0.0099)$ & $(0.0017)$ & $(0.0036)$ & $(0.0089)$ \\
\multirow{2}{*}{ South } & 1.5217 & 2.0948 & 2.6479 & 0.4622 & 0.8597 & 1.2577 \\
& $(0.0256)$ & $(0.0254)$ & $(0.0239)$ & $(0.0108)$ & $(0.0212)$ & $(0.0354)$ \\
\hline
\end{tabular}

Author's calculations. The first three columns refer to the estimations of the cumulative costs with a PPF without parental compensation (that is a model without equation 11). The second three columns refer to the model that includes equation 11. $\alpha=1$ corresponds to the case where the remote instruction is a perfect substitute of in person classes, $\alpha=0$ is the case where remote instruction has no effect on learning. The effective immediate cost corresponds to the share of a school year of learning lost due to the transition to remote learning. Jackknife standard errors in parenthesis.

under different assumptions regarding the effectiveness of the remote instruction policy adopted. The first set corresponds to a model of learning accumulation without an active role for parents in investing in their children to attenuate the gap with respect to the learning progression of the school syllabi. This is the original learning accumulation model as proposed by Kaffenberger and Pritchett $(2020,2021)$ without equation 20. The second set of results includes equation 18 and, as a result, consider the case in which parents invest in their children's learning to minimise the gap with respect to the school system learning progression. This comparison allows me to examine how sensitive is the model to the inclusion of an active parental investment function, which would bring the PPF model closer to the results from the parenting literature (Doepke et al., 2019).

In the first scenario, that without parental investments, the national average of the expected cumulative cost of the instructional disruption supposed by the COVID-19 pandemic ranges between the loss of one year of learning (if $\alpha=1$, the best-case scenario) and two years of learning (if $\alpha=0$, the worst-case scenario) with respect to a learning progression without a shock. In the second scenario, which considers the role of parental investments throughout the learning progression, the values are 0.1871 of a school year of learning for the best-case scenario and 0.9040 of a school year of learning for the worst-case scenario. In the two scenarios, these national averages hide substantial regional heterogeneity, and in particular, the south of the 
country is expected to be the most affected region regardless of the scenario considered.

Table 7. Average cumulative cost with respect to intended learning progression under different assumptions

\begin{tabular}{|c|c|c|c|c|c|c|}
\hline \multirow{2}{*}{ Region } & \multicolumn{3}{|c|}{ Without household compensating investment } & \multicolumn{3}{|c|}{ With household compensating investment } \\
\hline & $\alpha=1$ & $\alpha=0.5$ & $\alpha=0$ & $\alpha=1$ & $\alpha=0.5$ & $\alpha=0$ \\
\hline \multirow{2}{*}{ National } & 0.9162 & 1.3771 & 1.9797 & 0.1163 & 0.4003 & 0.8332 \\
\hline & $(0.0315)$ & $(0.0340)$ & $(0.0319)$ & $(0.0252)$ & $(0.0289)$ & $(0.0335)$ \\
\hline \multirow{2}{*}{ North } & 0.8433 & 1.2782 & 1.8812 & 0.0383 & 0.1998 & 0.9568 \\
\hline & $(0.0060)$ & $(0.0056)$ & $(0.0048)$ & $(0.0096)$ & $(0.0098)$ & $(0.0281)$ \\
\hline \multirow{2}{*}{ North West } & 0.9418 & 1.2829 & 1.8989 & 0.0948 & 0.2859 & 0.6581 \\
\hline & $(0.0108)$ & $(0.0078)$ & $(0.0071)$ & $(0.0202)$ & $(0.0197)$ & $(0.0288)$ \\
\hline \multirow{2}{*}{ Center North } & 0.5860 & 0.9413 & 1.5569 & 0.0288 & 0.1859 & 0.5484 \\
\hline & $(0.0056)$ & $(0.0065)$ & $(0.0253)$ & $(0.0124)$ & $(0.0106)$ & $(0.0163)$ \\
\hline \multirow{2}{*}{ Center } & 0.4795 & 0.9391 & 1.5639 & 0.1881 & 0.0852 & 0.4450 \\
\hline & $(0.0038)$ & $(0.0055)$ & $(0.0036)$ & $(0.0083)$ & $(0.0118)$ & $(0.0173)$ \\
\hline \multirow{2}{*}{ South } & 1.8858 & 2.0948 & 2.6479 & 0.8263 & 1.2238 & 1.6218 \\
\hline & $(0.0058)$ & $(0.0045)$ & $(0.0048)$ & $(0.0340)$ & $(0.0446)$ & $(0.0587)$ \\
\hline
\end{tabular}

Author's calculations. The first three columns refer to the estimations of the cumulative costs with a PPF without parental compensation (that is a model without equation 11). The second three columns refer to the model that includes equation 11. $\alpha=1$ corresponds to the case where the remote instruction is a perfect substitute of in person classes, $\alpha=0$ is the case where remote instruction has no effect on learning. The effective immediate cost corresponds to the share of a school year of learning lost due to the transition to remote learning. Jackknife standard errors in parenthesis.

As expected, the cumulative cost is smaller in the model that considers parental investments throughout a child's learning trajectory. However, the role of parental investments in mitigating the widening of the initial gap caused by the instructional disruption is more apparent when comparing the relationship between immediate and cumulative costs between both models. For example, under the assumption that no parental investment occurs, when $\alpha=1$, the cumulative costs are 3.32 times the immediate costs. Similarly, when $\alpha=0$, the average cumulative cost at the national level is 2.1397 times the immediate cost. In contrast, when parents are assumed to actively try to attenuate the disruption throughout the children's learning progression, the cumulative costs are smaller than the immediate cost. In this case, when $\alpha=1$ the national average cumulative cost represent s 0.6312 times the national average immediate cost, whereas when $\alpha=0$ the national average cumulative cost represents 0.9433 times the national average immediate cost.

However, it is essential to highlight that there are persistent costs of temporary instructional disruption even when parental investments are included in the model. This result is consistent with the empirical literature reviewed in the introduction and highlights the role of policy 
interventions in preventing this persistence. As my results indicate, parental investments can prevent the cumulative costs from increasing with respect to the immediate cost, but they are not enough to completely attenuate the cumulative effect of the temporal disruption. This is particularly true for families with fewer resources and, thus, a lower investment capacity in their children.

Table 8. Inequality in the magnitude of the cumulative cost

(Gini coefficient)

\begin{tabular}{|c|c|c|c|c|c|c|}
\hline \multirow{2}{*}{ Region } & \multicolumn{3}{|c|}{ Without household compensating investment } & \multicolumn{3}{|c|}{ With household compensating investment } \\
\hline & $\alpha=1$ & $\alpha=0.5$ & $\alpha=0$ & $\alpha=1$ & $\alpha=0.5$ & $\alpha=0$ \\
\hline National & 0.1935 & 0.1529 & 0.1015 & 0.3877 & 0.2896 & 0.1828 \\
\hline & & (0.0001) & $(0.0020)$ & (0.0001) & (0.0000) & $(0.0040)$ \\
\hline North & $\begin{array}{c}0.1061 \\
(0.0065)\end{array}$ & $\begin{array}{c}0.0884 \\
(0.0052)\end{array}$ & $\begin{array}{c}0.0575 \\
(0.0035)\end{array}$ & $\begin{array}{c}0.2863 \\
(0.0121)\end{array}$ & $\begin{array}{c}0.1719 \\
(0.0077)\end{array}$ & $\begin{array}{c}0.1869 \\
(0.0098)\end{array}$ \\
\hline North West & $\begin{array}{c}0.0820 \\
(0.0052)\end{array}$ & $\begin{array}{c}0.0805 \\
(0.0044)\end{array}$ & $\begin{array}{c}0.0495 \\
(0.0028)\end{array}$ & $\begin{array}{c}0.2187 \\
(0.0101)\end{array}$ & $\begin{array}{c}0.1095 \\
(0.0059)\end{array}$ & $\begin{array}{c}0.1168 \\
(0.0051)\end{array}$ \\
\hline Center North & $\begin{array}{c}0.0879 \\
(0.0055)\end{array}$ & $\begin{array}{c}0.0783 \\
(0.0046)\end{array}$ & $\begin{array}{c}0.0555 \\
(0.0028)\end{array}$ & $\begin{array}{c}0.1852 \\
(0.0094)\end{array}$ & $\begin{array}{c}0.0817 \\
(0.0036)\end{array}$ & $\begin{array}{c}0.0884 \\
(0.0039)\end{array}$ \\
\hline Center & $\begin{array}{c}0.0992 \\
(0.0068)\end{array}$ & $\begin{array}{c}0.0644 \\
(0.0046)\end{array}$ & $\begin{array}{c}0.0402 \\
(0.0027)\end{array}$ & $\begin{array}{c}0.1291 \\
(0.0066)\end{array}$ & $\begin{array}{c}0.0773 \\
(0.0049)\end{array}$ & $\begin{array}{c}0.0906 \\
(0.0051)\end{array}$ \\
\hline South & $\begin{array}{c}0.1179 \\
(0.0055)\end{array}$ & $\begin{array}{c}0.0846 \\
(0.0037)\end{array}$ & $\begin{array}{c}0.0662 \\
(0.0028)\end{array}$ & $\begin{array}{c}0.1629 \\
(0.0066)\end{array}$ & $\begin{array}{c}0.1724 \\
(0.0049)\end{array}$ & $\begin{array}{c}0.1894 \\
(0.0051)\end{array}$ \\
\hline
\end{tabular}

Author's calculations. The first three columns refer to the estimations of the cumulative costs with a PPF without parental compensation (that is a model without equation 11). The second three columns refer to the model that includes equation 11. $\alpha=1$ corresponds to the case where the remote instruction is a perfect substitute of in person classes, $\alpha=0$ is the case where remote instruction has no effect on learning. The effective immediate cost corresponds to the share of a school year of learning lost due to the transition to remote learning. Jackknife standard errors in parenthesis.

To analyse the effect of varying the assumptions on parental compensating investments and the efficacy of public policy, table 8 shows the Gini coefficient of the distribution of cumulative costs under the scenarios analysed above. As expected, the inclusion of parental investments throughout the learning progression results in a more unequal distribution of the cumulative costs than when this factor is not considered. The reason is that when this factor is excluded, the inequality in household resources only affects the immediate costs, after which it stops playing a role in the model. However, when parental investments are included, the inequality in their distribution translates directly into inequality in the cumulative costs experienced by children. The unequal impacts of the COVID-19 class suspension can be seen in figure 1. As can be seen, those who lie below the median of the economic and educational resources joint distribution are the ones who suffer the most persistent effect in terms of magnitude. In contrast, those at the top of the distribution can recover from the short-run shock and do not experience a persistent negative effect. 
Figure 1. Distribution of impact across percentiles of resource distribution

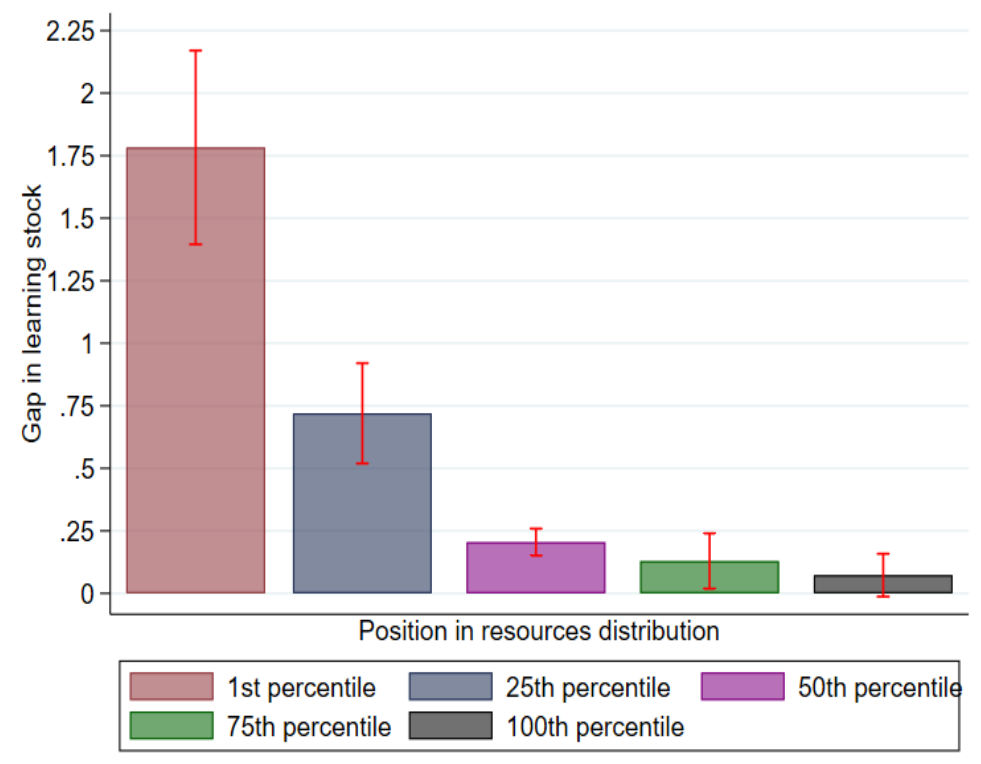

The results from my preferred specification (that which includes parental attenuation) suggest that as a result of the temporary instructional disruption, the knowledge stock of the Mexican children who experienced the shock at sixth grade will be, on average, between 0.1871 and 0.9040 school years of learning when they reach ninth grade. In other words, in the best-case scenario, at the end of their primary education cycle, the cohort who experienced the shock in sixth grade will have the learning stock equivalent to a student who missed two months of schooling in a scenario without the pandemic. In the worst-case scenario, they will have the learning stock of a child who missed almost an entire year of in-person instruction. However, this average loss in years of learning masks substantial regional heterogeneity. For the children from the Centre region, the expected loss of years of learning lies between 10\% (a month of in-person instruction) and $76 \%$ of a school year of learning progression (7 months of instruction). In contrast, the expected cost for the children from the South region lies between $40 \%$ of a school year of learning (about four months of instruction) and a school year and a quarter of learning. These results already consider the role of parental effort in mitigating the ripple effects of the temporary disruption, highlighting the importance of complementary public policy aimed at reinforcing that mitigation effort. 


\section{Final Remarks}

This paper's first set of implications has to do with the recent literature on models of instructional disruptions and their costs (Kaffenberger and Pritchett, 2020b, 2021; Kaffenberger, 2021; Neidhöfer et al., 2021). Firstly, this literature has sought to explicitly model the mechanism through which instructional disruptions affect learning acquisition both in the short and the long run. However, as these papers come from two different strands of the literature (development economics and education studies), their modelling strategies have remained isolated from each other. In this paper, I show that the insights from both types of models can be put together in a cohesive framework that matches the empirical findings that initially motivated the literature. Secondly, in this paper, I show that it is possible to integrate continuous parental investments into this framework, supplementing a gap in the literature and closening the gap between learning progression models based on the Potential Pedagogical Function and more traditional economic models. The inclusion of this factor does not prevent the model from replicating the persistence effect of temporary shocks into the learning acquisition process. Furthermore, the model highlights that the explicit inclusion of economic resources as part of the resources of the household for attenuating the impacts of a temporary shock provides information not captured by the educational resources, which has been the only variable used so far in the literature (Neidhöfer et al., 2021).

The second set of implications refers to the empirical application of the model. The results suggest that the instructional disruption caused by the COVID-19 pandemic will cause a persistent learning loss with respect to the counterfactual without the disruption in the Mexican case. The magnitude of the loss varies by region and depends on the performance of the remote learning model implemented as a substitute for in-person classes. If the remote instruction model were a perfect substitute, the average loss in the country for the cohort affected would be equivalent in terms of learning gains lost to missing a month of in-person classes. However, if the remote instruction model failed, the loss would be, on average, equivalent to missing a whole year of learning. These average results are worse in the south of the country, a region that is already behind the rest of the country in learning progression and scholarly attainment. Given that these results already consider the effort performed by households in mitigating this learning

loss, the policy implications are clear. In order to minimise the effect of the pandemic shock in the future stock of learning of the affected children, it is necessary to implement a remedial education policy geared towards the students who inhabit households with less resources. 


\section{References}

Andrabi, Tahir, Benjamin Daniels, and Jishnu Das, "Human Capital Accumulation and Disasters: Evidence from the Pakistan Earthquake of 2005," Journal of Human Resources, 2021.

Bau, Natalie, Jishnu Das, and Andres Yi Chang, "New evidence on learning trajectories in a low-income setting," International Journal of Educational Development, 2021, 84, 102430.

Beatty, Amanda, Emilie Berkhout, Luhur Bima, Menno Pradhan, and Daniel Suryadarma, "Schooling progress, learning reversal: Indonesia's learning profiles between 2000 and 2014," International Journal of Educational Development, 2021, 85, 102436.

Belot, Michèle and Dinand Webbink, "Do Teacher Strikes Harm Educational Attainment of Students?," Labour, 2010, 24 (4), 391-406.

Ben-Porath, Yoram, "The Production of Human Capital and the Life Cycle of Earnings," Journal of Political Economy, 1967, 75 (4), 352-365.

Bowles, Samuel, Towards an Educational Production Function, NBER,

Campos-Vázquez, Raymundo M. and Luis Monroy-Gómez-Franco, “¿El crecimiento económico reduce la pobreza en México?," Revista de Economi Mexicana. Anuario UNAM, 2016, 1 (1), 140-185.

Coleman, James, Ernest Campbell, Carol Hobson, James McPartland, Alexander Mood, Frederick Weinfeld, and Robert York., "Equality of Educational Opportunity," Technical Report, Washington D.C. 1966.

Crawfurd, Lee, "Accounting for repetition and dropout in contemporaneous cross-section learning profiles: Evidence from Rwanda," International Journal of Educational Development, $2021,85,102443$.

Cunha, Flavio, James J. Heckman, and Susanne M. Schennach, "Estimating the Technology of Cognitive and Noncognitive Skill Formation," Econometrica, 2010, 78 (3), 883-931.

de la Torre, Rodolfo and Roberto Vélez-Grajales, Informe sobre Desarrollo Humano. México 2016: Desigualdad y Movilidad, United Nations Development Program, 2016.

Delajara, Marcelo, Raymundo M. Campos-Vazquez, and Roberto Velez-Grajales, "The regional geography of social mobility in Mexico," Regional Studies, 2021, pp. 1-14. 
Diario Oficial de la Federación, "Acuerdo 26/12/20 por el que se establecen las orientaciones pedagógicas y los criterios para la evaluación del aprendizaje para la educación preescolar, primaria y secundaria en el periodo de contingencia sanitaria generada por el virus SARSCoV2 (COVID-19) para el ciclo escolar 2020-2021.," 12 2020. https://www. dof.gob.mx/ nota_detalle $\cdot$ php? codigo $=5608934 \&$ fecha $=28 / 12 / 2020$.

Doepke, Matthias, Giuseppe Sorrenti, and Fabrizio Zilibotti, "The Economics of Parenting," Annual Review of Economics, 2019, 11 (1), 55-84.

Filmer, Deon and Lant H. Pritchett, "Estimating Wealth Effects without Expenditure Data-or Tears: An Application to Educational Enrollments in States of India," Demography, 2001, 38 (1), 115-132.

Hanushek, Eric A., "Conceptual and Empirical Issues in the Estimation of Educational Production Functions," The Journal of Human Resources, 1979, 14 (3), 351-388.

_, "Publicly provided education," in A. J. Auerbach and M. Feldstein, eds., Handbook of Public Economics, Vol. 4 of Handbook of Public Economics, Elsevier, 2002, chapter 30, pp. 2045-2141.

_ , "Education Production Functions: Developed Country Evidence," in Penelope Peterson, Eva Baker, and Barry McGaw, eds., International Encyclopedia of Education (Third Edition), third edition ed., Oxford: Elsevier, 2010, pp. 407-411.

Heckman, James J. and Stefano Mosso, "The Economics of Human Development and Social Mobility," Annual Review of Economics, 2014, 6 (1), 689-733.

Ichino, Andrea and Rudolf Winter-Ebmer, "The Long-Run Educational Cost of World War II," Journal of Labor Economics, 2004, 22 (1), 57-87.

Instituto Nacional de Estadística y Geografía, "Encuesta para la Medición del Impacto del COVID-19 en la Educación. Presentación de resultados," Technical Report, Instituto Nacional de Estadística y Geografía, Aguascalientes 2021.

Jaume, David and Alexander Willén, "The Long-Run Effects of Teacher Strikes: Evidence from Argentina," Journal of Labor Economics, 2019, 37 (4), 1097-1139.

Kaffenberger, Michelle, "Modelling the long-run learning impact of the Covid-19 learning shock: Actions to (more than) mitigate loss," International Journal of Educational Development, 2021, 81, 102326.

- and Lant Pritchett, "Aiming higher: Learning profiles and gender equality in 10 lowand middle-income countries," International Journal of Educational Development, 2020, 79, 102272 . 
_ and _ , "Failing to Plan? Estimating the Impact of Achieving Schooling Goals on Cohort Learning," Working Paper 20083, Research on Improving Systems of Education 2020.

_ and _ , "A structured model of the dynamics of student learning in developing countries, with applications to policy," International Journal of Educational Development, 2021, 82, 102371.

Leibowitz, Arleen, "Home Investments in Children," Journal of Political Economy, 1974, 82 (2), S111-S131.

Marcotte, Dave E. and Steven W. Hemelt, "Unscheduled School Closings and Student Performance," Education Finance and Policy, 07 2008, 3 (3), 316-338.

McKenzie, David, "Measuring Inequality with Asset Indicators," Journal of Population Economics, 2005, 18 (2), 229-260.

Meng, Xin and Guochang Zhao, "The long shadow of a large scale education interruption: The intergenerational effect," Labour Economics, 2021, 71, 102008.

Neidhöfer, Guido, Nora Lustig, and Mariano Tommasi, "Intergenerational transmission of lockdown consequences: Prognosis of the longer-run persistence of COVID-19 in Latin America," Journal of Economic Inequality, 2021.

Poirier, Mathieu J. P., Karen A. Grépin, and Michel Grignon, "Approaches and Alternatives to the Wealth Index to Measure Socioeconomic Status Using Survey Data: A Critical Interpretive Synthesis," Social Indicators Research: An International and Interdisciplinary Journal for Quality-of-Life Measurement, February 2020, 148 (1), 1-46.

Pritchett, Lant and Justin Sandefur, "Girls' schooling and women's literacy: schooling targets alone won't reach learning goals," International Journal of Educational Development, 2020, 78, 102242.

Prix, Irene and Jani Erola, "Does death really make us equal? Educational attainment and resource compensation after paternal death in Finland," Social Science Research, 2017, 64, $171-183$.

Ramírez-Raymundo, Rodolfo, José Gutiérrez-García, and Magdalena Rodríguez de la Huerta, "Orientaciones para apoyar el estudio en casa de niñas, niños y adolescentes. Educación preescolar, primaria y secundaria," Technical Report, Secretaría de Educación Pública, Mexico City 2021. 
Sacerdote, Bruce, "When the Saints Go Marching Out: Long-Term Outcomes for Student Evacuees from Hurricanes Katrina and Rita," American Economic Journal: Applied Economics, January 2012, 4 (1), 109-35.

Todd, Petra E. and Kenneth I. Wolpin, "On the Specification and Estimation of the Production Function for Cognitive Achievement*," The Economic Journal, 2003, 113 (485), F3-F33.

Wittenberg, Martin and Murray Leibbrandt, "Measuring Inequality by Asset Indices: A General Approach with Application to South Africa," Review of Income and Wealth, 2017, 63 (4), 706-730. 